\title{
Contagion effect analysis of US to East Asia Stock Markets
}

\author{
$\underline{\text { R. Tansuchat }}^{\text {a }}$ \\ ${ }^{a}$ Faculty of Economics, Chiang Mai University, Chiang Mai Thailand \\ Email: roengchaitan@gmail.com
}

\begin{abstract}
The economy of East Asia countries depends on the US economy through international trade, international finance, and exchange rate policies. The objective of this paper is to investigate contagion effect between the East Asia stock markets and the US stock market by using the Markov Switching DCC-GJR GARCH model. The information about the contagion effect among the East Asia and USA stock market indexes was gathered daily during the period of July 1, 2009 to July 5, 201 , which was after the financial crisis. Since the dynamic condition correlation may shift because of regime switching, the conditional correlations were estimated by the application of Markov Switching DCC-Skew-GJR GARCH, which can be divided into high and low correlation regimes. The results showed that the conditional correlation is not constant with positive value. In addition, they can be separated into two regimes, including regime 1 with high conditional correlation (bear market), and regime 2 with low conditional correlation (bull market). The highest correlation could be observed between the USA and Japan Stock markets, followed by between the USA and China stock markets. Furthermore, the positive conditional correlations were found between the USA and other East Asia stock markets, and among East Asia stock markets themselves. This has concurred with the current situation when the effects of shocks such as the trade policy between China and USA not only created the impact between the two countries, but the impacts also spread to neighboring countries in East Asia. The contagion test results of this study confirms the occurrence of the contagion effect.
\end{abstract}

Keywords: Contagion, Markov-switching, Dynamic Conditional correlation, East Asia Stock Index, US Stock market 


\section{INTRODUCTION}

Under the global financial system "Neo-Liberal Regime", there are no guarantees to ensure that countries with strong economy or "institutions" could avoid the effects of "Financial Crisis" that occurs in another country regardless of the distance between them. A large amount of evidence collected since the economic crisis in 1997 (Tom Yum Kung Crisis) demonstrates that when there is a financial crisis in one country, the effects of such crisis often spreads to neighbouring countries located in the same region as well as countries with similar or weaker economic backgrounds, or even countries whose economy seems to be strong. Indeed, according to the definition of Contagion Effects, the widespread effect occurs not only during the financial crisis, but it can also refer to the transmission of shocks across the country under either normal or bad economic circumstances.

Transmission of such shocks may occur through "Fundamentals-based Contagion" in various ways, whether through (1) global channels such as oil prices, interest rates, and commodity prices, (2) trade channels such as exchange rates, competitiveness, and income of partner countries, and (3) financial channels such as international investment, and foreign borrowing. It may also occur through "Uncontrollable-predictable factors" (Pure Contagion), such as changes in investor expectations, herding behaviour or Wake-up call effects. At present, contagion effect is becoming more violent and widespread under the new "liberal" institutions. If a country has more financial liberalization, especially the capital account liberalization, the financial crisis is likely to happen in that country.

After the hamburger crisis, many countries have potential and economic stability, such as Japan, China, Taiwan and South Korea, resulting in investors' increasing interest in investing. Nowadays, the economy of East Asia countries depend on the US economy through international trade (import-export), international finance (direct and indirect investment), and exchange rate policies. Therefore, the direction of these stock markets is determined by one another and shock from one country may spread to another country.

The distinction between contagion and spillover effect is difficult to distinguish. The contagion means that prior to the shock there is no dependence between the markets. However, after the shock the dependence between the market distinctly increases. Therefore, contagion effect is important for investors and the portfolios of multiple international markets that they hold on. Previous literature confirmed that the contagion effect existed between the inter-financial sector (Kodres and Pritsker 2002, Allen and Gale 2000, and Chitkasame and Tansuchat 2019), especially the shock from the developed stock market (Chiang et al. 2007, Sible 2012, and Mollah 2015), international trade (Salgado et al. 2000, and Kali and Reyes 2010), and financial shock (Dungey et al. 2001, Longstaff 2010, Aloui et al. 2011, Dimitriou et al. 2013, and Mendoza and Quadrini 2010).

Contagion effect can be tested with many approaches. First, it can be tested based on correlation coefficients, which is the easiest method. If a correlation coefficient after shock encounter shows a significant increase, the contagion will happen (Loretan and English 2000, Forbes and Rigobon 2002 Corsetti et al. 2005 Cominetta 2016, and Zhanyun 2018). For the second method, contagion is tested based on volatility analysis, which analyses transmission mechanism of variance and covariance between countries, particularly multivariate conditional volatility models such as constant conditional correlation GARCH (CCC-GARCH) model of Bollerslev (1990) and dynamic conditional correlation GARCH (DCC-GARCH) model by Engle (2002) (Chiang, Jeon, and Li 2007 and Sun and Zhang 2009). In the past, there were some studies about Contagion effect from the U.S. Stock Market to East Asia stock markets using GARCH models such as Chancharoenchai and Dibooglu (2006), Inchang Hwang and et al. (2010), Chien-Chung Nieh and et al. (2011), SibelCel1k (2012) and Hemche and et al. (2016)

However, the dynamic condition correlation may shift as a result of regime switching. In 1989, Hamilton proposed the Markov Switching Regression model, a nonlinear model in which coefficients can change according to the state of the data. Therefore, the Markov Switching Regression model is used in time series such as bear market and bull market of stock. (Schaller and Norden (1997), Chauvet and Potter (2000), Linne (2002), Hess (2003), Liu and et. al. (2012), Chaudhuri and Kumar (2015), Tansuchat and Yamaka (2018) and Wongutai and et. al. (2018)). Moreover, many recent studies, such as Tofoli, Zigemann and Silva Filho (2013) and Karimalis and Nimokis (2014), have found that the conditional correlation during markets upturn is less than during market downturns. Thus, this confirms the high dependence regime as market downturn regime and low dependence regime as market upturns regime (Pastpipatkul and et al. (2016)).

Thus, the objective of this paper is to investigate contagion effect among the East Asia stock markets and US stock market by using the Markov Switching DCC-GJR GARCH model, which was introduced by Billo and Caporin (2005). The rest of this paper is organised as follows. The following sector provides methodology of Markov Switching DCC-Skew-GJR GARCH. Section 3 presents the data. Section 4 reports the empirical results and the last section concludes the study. 


\section{METHODOLOGY}

\subsection{GJR-GARCH with Skew Distribution}

Regarding the analysis of time series data, the GARCH family models have been widely used to analyse and forecast volatility. In this study, we apply GJR-GARCH model (Glosten, et al. 1993), which assumes a specific parametric form for the conditional heteroscedasticity with leverage effect;

$$
\begin{aligned}
r_{t} & =\mu_{t}+\varepsilon_{t}, \varepsilon_{t}=u_{t} \sqrt{\sigma_{t}^{2}} \\
\sigma_{t}^{2} & =\omega+\beta \sigma_{t-1}^{2}+\left(\alpha+\gamma I_{t-1}\right) \varepsilon_{t-1}^{2}
\end{aligned}
$$

where $I_{t}$ is indicator function, and $u_{t}$ is skew distribution which is based on Fernandez and Steel (1998) as

$$
f\left(u_{i, t} \mid \xi\right)=\frac{2}{\xi+\xi^{-1}}\left[f\left(\xi u_{i, t}\right) \mathrm{H}\left(-u_{i, t}\right)+f\left(\xi^{-1} u_{i, t}\right) \mathrm{H}\left(u_{i, t}\right)\right]
$$

where $\xi \in \mathrm{R}^{+}$is a shape parameter indicating degree of asymmetry. $\mathrm{H}(u)=(1+\operatorname{sign}(n)) / 2$ is Heaviside unit step function.

\subsection{Dynamic Conditional Correlation GARCH (DCC-GJR GARCH) model}

Engle (2002) developed the dynamic conditional correlation GARCH (DCC-GARCH) model to solve the constant correlation problem of constant conditional correlation GARCH (CCC-GARCH) model (Bollerslev 1990).

$$
H_{t}=D_{t} R_{t} D_{t}
$$

where $H_{t}$ is $n \times t$ matrix of conditional variance the at time $t, R_{t}$ is conditional correlation matrix at time $t$ and $D_{t}$ is diagonal matrix of $\sigma_{t}^{2}$ at time $t$ as follows:

$$
D_{t}=\operatorname{diag}\left\{\sqrt{\sigma_{1 t}}, \ldots, \sqrt{\sigma_{n t}}\right\}
$$

After, the volatility from the GJR-GARCH model (2.1), the result is in the form of a vector. Thus, it is converted to a matrix (Orskaug 2009).

$$
D_{i, t}=\left[\begin{array}{cccc}
\sqrt{\sigma_{1 t}} & 0 & \cdots & 0 \\
0 & \ddots & & \vdots \\
\vdots & & \ddots & 0 \\
0 & \cdots & 0 & \sqrt{\sigma_{n t}}
\end{array}\right]
$$

The result will be in the form of a correlation matrix. The equation is as follows (Billio and Caporin, 2005).

$$
\begin{gathered}
R_{t}=\operatorname{diag}\{Q\}_{t}^{-1} Q_{t} \operatorname{diag}\{Q\}_{t}^{-1} \\
Q_{t}=\left(1-\theta_{1}-\theta_{2}\right) \bar{Q}+\theta_{1} \varepsilon_{t-1} \varepsilon_{t-1}^{\prime}+\theta_{2} Q_{i, t-1}
\end{gathered}
$$

where $R_{i, t}$ is conditional correlation matrix at time $t$ and $Q_{i, t}$ is conditional correlation matrix with time varying at time $t \cdot \bar{Q}=\frac{1}{T} \sum_{t=1}^{T} \varepsilon_{t-1} \varepsilon_{t-1}^{\prime}$ is the unconditional covariance matrix of the standardized errors $\varepsilon_{t}$. $\theta_{1}$ and $\theta_{2} \theta_{i, 2}$ are parameters in range $0<\theta_{1}+\theta_{2}<1$

2.3 Markov Switching Dynamic Conditional Correlation GARCH (MS-DCC- GJR GARCH) model The Markov switching model allows the parameter switch between states. Based on the Markov process, all parameters are controlled by the state variable $\left(s_{t}\right)$ with probability $\left(p_{i j}\right)$ (Hamilton 1989):

$$
\operatorname{Pr}\left(s_{t}=j \mid s_{t-1}=i\right)=p_{i j}, \sum_{j=1}^{k} p_{i j}=1 \text {, where } i=1, \ldots, k \text {. }
$$

This study is based on the two-state Markov switching model. The first step is as follows:

$$
\operatorname{Pr}\left(s_{t}=j \mid s_{t-1}=i\right)=p_{i j}, \sum_{j=1}^{2} p_{i j}=1 \text {, where } i=1, \ldots, 2 .,
$$

where $p_{i j}$ is the probability of switching from regime $i$ to $j$ regime and $\sum_{j=1}^{2} p_{i j}=1$ in order to separate the non-linear function into two states.

Billo and Caporin (2005) proposed the Markov Switching DCC-GARCH model by combining the Markov Switching with DCC-GARCH model so it can be written as follows.

$$
Q_{t,\left(s_{t}=i\right)}=\left(1-\theta_{1,\left(s_{t}=i\right)}-\theta_{2,\left(s_{t}=i\right)}\right) \bar{Q}_{t,\left(s_{t}=i\right)}+\theta_{1,\left(s_{t}=i\right)} \varepsilon_{t-1,\left(s_{t}=i\right)} \varepsilon_{t-1,\left(s_{t}=i\right)}^{\prime}+\theta_{2,\left(s_{t}=i\right)} Q_{t-1,\left(s_{t}=i\right)},
$$


where $Q_{t,\left(s_{t}=i\right)}$ conditional correlation matrix with time varying at time $t$ in regime $s_{t}$ and $s_{i, t-1}$ is state variable of $i$ at time $t-1$. So, the equations can be written as follows:

$$
\begin{aligned}
& r_{s_{t}}=\mu+u_{s_{t}} \sqrt{\sigma_{s_{t}}^{2}} \\
& H_{s_{t}}=D_{s_{t}} R_{s_{t}} D_{s_{t}} \\
& R_{s_{t}}=\operatorname{diag}\{Q\}_{s_{t}}^{-1} Q_{s_{t}} \operatorname{diag}\{Q\}_{s_{t}}^{-1} \\
& D_{t}=\operatorname{diag}\left\{\sqrt{\sigma_{1 t}}, \ldots, \sqrt{\sigma_{n t}}\right\}
\end{aligned}
$$

where $\boldsymbol{s}_{t}$ is the state variable under the probability of equation (2.10) and $\sigma_{t}^{2}$ is the volatility of $\varepsilon_{t}$ at the time $t$ in regime $\boldsymbol{s}_{\boldsymbol{t}}$.

\section{DATA}

The data used in this study are collected from the daily return from six closing stock price index of the major East Asia stock markets, namely Hong Kong Stock Exchange (Hongkong: HSI), Korea Exchange (South Korea: KOSPI), Tokyo Stock Exchange (Japan: NIKKEI), Shanghai Stock Exchange (China: SHCOMP), Taiwan Stock Exchange (Taiwan), and USA stock market with S\&P 500. The data were obtained from Bloomsburg database, starting from 1 July 2009 and ending on 5 July 2019, with the total of 2,613 observations.

Table 1. Descriptive statistics

\begin{tabular}{|c|c|c|c|c|c|c|}
\hline & Shanghai & Hang Seng & KOSPI & NIKEI & Taiwan & USA \\
\hline Mean & 0.0000 & 0.0002 & 0.0002 & 0.0003 & 0.0002 & 0.0005 \\
\hline Median & 0.0000 & 0.0000 & 0.0001 & 0.0000 & 0.0002 & 0.0004 \\
\hline Maximum & 0.0559 & 0.0551 & 0.1128 & 0.1323 & 0.0652 & 0.1096 \\
\hline Minimum & $0.0886-$ & $0.0602-$ & $0.0642-$ & $0.1115-$ & $0.0652-$ & $0.0690-$ \\
\hline Std. Dev. & 0.0137 & 0.0113 & 0.0092 & 0.0128 & 0.0091 & 0.0092 \\
\hline Skewness & $0.9305-$ & $0.3075-$ & $0.4991-$ & $0.5552-$ & $0.6274-$ & $0.4668-$ \\
\hline Kurtosis & 8.3771 & 11.4582 & 10.0360 & 9.9413 & 7.0694 & 11.8822 \\
\hline Jarque-Bera & $4259.764^{*}$ & $663.3788^{*}$ & $2281.311^{*}$ & $3596.417^{*}$ & $2023.182^{*}$ & $2367.345^{*}$ \\
\hline ADF Test & $-49.65^{*}$ & $-50.46^{*}$ & $-50.64^{*}$ & $-53.84^{*}$ & $-49.08^{*}$ & $-52.75^{*}$ \\
\hline
\end{tabular}

Table 1 shows the descriptive statistics of the returns of the five East Asia and USA stock market indexes. The skewness of each return series is less than one, which means the distribution is negatively skewed. The Kurtosis is greater than 3, meaning leptokurtic. Therefore, the Maximum Bayes Factor (MBF) transformed from $p$-value for Jarque-Bera statistic strongly reject the normal distribution hypothesis. Finally, the MBF of ADF-test for nonstationary test reject the null hypothesis of the unit root.

\section{EMPIRICAL RESULT}

Table 2: Estimation result.

\begin{tabular}{|c|c|c|c|c|c|c|}
\hline & Hong Kong & China & Korea & Japan & Taiwan & USA \\
\hline$\alpha$ & 0.000 & $0.053^{* * *}$ & 0.014 & 0.000 & $0.016^{* * *}$ & 0.000 \\
\hline$\beta$ & $0.999^{* * *}$ & $0.942^{* * *}$ & $0.939^{* * *}$ & $0.913^{* * *}$ & $0.842^{* * *}$ & $0.937^{* * *}$ \\
\hline$\gamma$ & 0.000 & 0.009 & 0.066 & 0.125 & $0.199^{* * *}$ & $0.087 * * *$ \\
\hline$\alpha+\beta$ & 0.999 & 0.995 & 0.952 & 0.913 & 0.858 & 0.937 \\
\hline Skew & $1.460^{* * *}$ & $0.971^{* * *}$ & $0.940^{* * *}$ & $0.914^{* * *}$ & $0.943^{* * *}$ & $0.896^{* * *}$ \\
\hline Shape & $2.010^{* * *}$ & $3.722^{* * *}$ & $6.233^{* * *}$ & $5.127^{* * *}$ & $5.316^{* * *}$ & $5.609^{* * *}$ \\
\hline \multicolumn{2}{|c|}{0.0824} & \multicolumn{2}{|c|}{$\theta_{1,\left(s_{t}=2\right)}$} & 0.0723 \\
\hline \multicolumn{2}{|c|}{$\theta_{1,\left(s_{t}=1\right)}$} & \multicolumn{2}{|c|}{$\theta_{2,\left(s_{t}=2\right)}$} & 0.8766 \\
\hline \multicolumn{2}{|c|}{$\theta_{2,\left(s_{t}=2\right)}$} & \multicolumn{2}{|c|}{1.0322} & $\theta_{1,\left(s_{t}=2\right)}+\theta_{2,\left(s_{t}=2\right)}$ & 0.9489 \\
\hline
\end{tabular}

\subsection{Empirical Result of MS-DCC-GJR GARCH $(1,1)$}

Table 2 represents the results of MS-DCC-GJR GARCH $(1,1)$. This model provides dependent variance equation of two regimes. The estimated parameters are statistically siginificant and greather than zero, meaning 
that the error term and the volatility in the past have positive effect on the volatily at time $t$. The estimated $\gamma$ parameters are statistically significant only Taiwan and USA stock markets, meaning that they have leverage effect and bad new increases volaitliy. In addition, the estimated shape and skew coefficience comfirm that the East Asia and USA stock index returns are asymmetrically distributed.

The unconditional volatility in each regime can be measured by $\alpha+\beta$ which is close to one, indicating that volatility shocks are quite persistent. We found that Hong Kong stock market accounted for the highest volatility persistence, at 0.999 , while Taiwan stock market made up the lowest volatility persistence, at 0.858 . Furthermore, we found that all markets of East Asia, together with USA stock market indexes, had high fluctuation major factors, which are considered external factors, such as QE.

Moreover, many recent studies, such as Tofoli, Zigemann and Silva Filho (2013) and Karimalis and Nimokis (2014), have found that the conditional correlation during markets upturn is less than during market downturns. Thus, this confirms the high dependence regime as market downturn regime and low dependence regime as market upturns regime (Pastpipatkul and et al. (2016)). Based on the result, the sum of $\theta_{1,\left(s_{t}=1\right)}+\theta_{2,\left(s_{t}=1\right)}$ is 1.0322 while the sum of $\theta_{1,\left(s_{t}=2\right)}+\theta_{2,\left(s_{t}=2\right)}$ is 0.9489 . Since this summation refers to the correlation persistence and can explain market situation, the regime 1 refers to bear market (high correlation regime) and the regime 2 refers to bull market (low correlation regime).

Table 3 presents the transition probability matrix of the model. The probability of regime switching from regime 1 to regime 2 is 0.029 while that of switching from regime 2 to regime 1 is 0.739 . This result suggests a higher probability for regime 1 (bear market) when compared to regime 2, which concurs with the pot of regime probabilities for all returns in figure 2 .

Table 3. Transition probability matrix

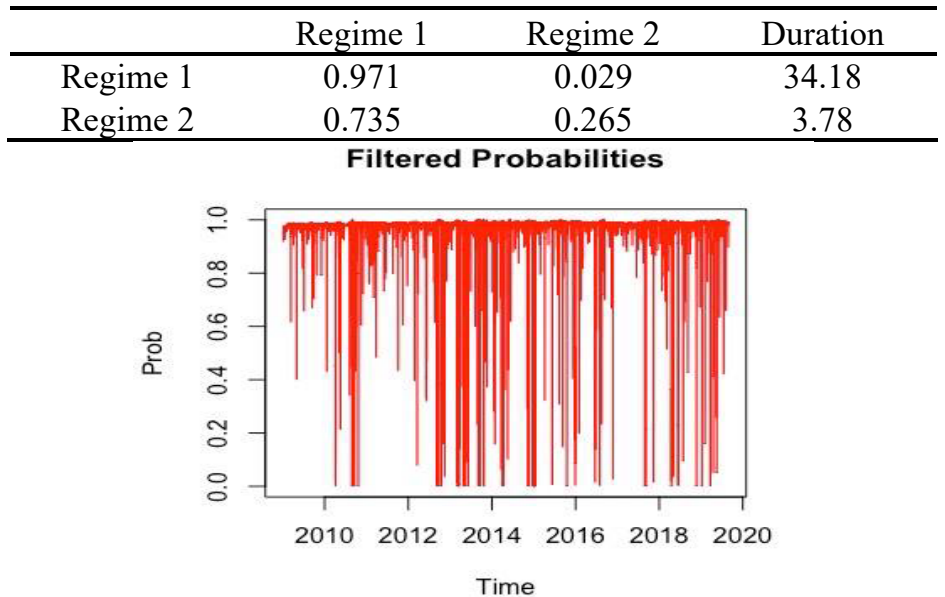

Figure 2. Filtered Probabilities

\subsection{The Mean of Dynamic Conditional Correlation}

Table 4. Mean of dynamic conditional correlation of East Asia include USA stock markets in regime 1 and 2 (High and low correlation regime)

\begin{tabular}{|}
\begin{tabular}{|c|c|c|c|c|c|c|}
\hline Regime & HongKong & China & Korea & Japan & Taiwan & USA \\
\hline Regime 1 (High Regime) \\
\hline HongKong & 1 & 0.8113 & 0.8014 & 0.7978 & 0.8013 & 0.8046 \\
\hline China & 0.8113 & 1 & 0.9185 & 0.8861 & 0.8773 & 0.9224 \\
\hline Korea & 0.8014 & 0.9185 & 1 & 0.9269 & 0.9113 & 0.8865 \\
\hline Japan & 0.7978 & 0.8861 & 0.9269 & 1 & 0.9183 & 0.9318 \\
\hline Taiwan & 0.8013 & 0.8773 & 0.9113 & 0.9183 & 1 & 0.9092 \\
\hline USA & 0.8046 & 0.9224 & 0.8865 & 0.9318 & 0.9092 & 1 \\
\hline Regime 2 (Low Regime) & \multicolumn{7}{|l}{} \\
\hline HongKong & 1 & 0.6054 & 0.5867 & 0.5767 & 0.5860 & 0.5919 \\
\hline China & 0.6054 & 1 & 0.8205 & 0.7482 & 0.7311 & 0.8298 \\
\hline Korea & 0.5867 & 0.8205 & 1 & 0.8405 & 0.8040 & 0.7503 \\
\hline Japan & 0.5767 & 0.7482 & 0.8405 & 1 & 0.8182 & 0.8505 \\
\hline Taiwan & 0.5860 & 0.7311 & 0.8040 & 0.8182 & 1 & 0.7994 \\
\hline USA & 0.5919 & 0.8298 & 0.7503 & 0.8505 & 0.7994 & 1 \\
\hline
\end{tabular}
\end{tabular}


Table 4 shows the mean or average of dynamic conditional correlation of each regime. In case of regime 1 , most mean correlations are higher than 0.9 and close to 1 . This shows that they are moving in the same direction of a high correlation regime, which means that when one country experiences an economic meltdown, other countries will also experience it. USA and Japan stock market indexes accounted for the highest value of conditional correlation, at 0.9318 , which means they have a strongest relationship in bear market (one country experiences an economic meltdown, other countries will also experience it), followed by China and USA stock markets. Glick and Rose (1999) and Kaminsky and Reinhart (2001) explained this phenomenon as attributable to many factors especially trade linkages, which explains cross-country correlations in stock markets pressure during crisis or trade war period. In case of low correlation regime (bull market), the East Asian and USA stock market indexes correlations are positive. The USA and Japan stock market indexes pair accounted for the highest value of conditional correlation $(0.8505)$ while the lowest conditional correlation belonged to Japan and Hong Kong stock market indexes pair (0.5767).

\section{DISCUSSION AND CONCLUSION}

The economy of an East Asia country depends on the US economy through international trade, international finance, and exchange rate policies. This study investigates the contagion effect among the East Asia and USA stock market indexes after financial crisis. This paper has used the daily data from the period from July 1, 2009 to July 5,2019. Since the dynamic condition correlation may shift because of regime switching, the conditional correlations were estimated by the application of Markov Switching DCC-Skew-GJR GARCH, which can be divided into high and low correlation regime. The results showed that the data exhibited a regime shift in the conditional correlation, and they had positive values. The highest correlation is between the USA and Japan Stock markets, followed by the USA and China stock markets. In addition, the positive conditional correlations were found between the USA and other East Asia stock markets, and among East Asia stock markets. This concurs with the current situation that the effects of shocks such as the trade policy between China and USA not only created the impact between the two countries, but the impacts also spread to neighboring countries in East Asia.

\section{REFERENCES}

Allen, F., and Gale, D. (2000). Financial contagion. Journal of political economy, 108(1), 1-33.

Aloui, R., Aïssa, M.D.B. and Nguyen, D. K. (2011). Global financial crisis, extreme interdependences, and contagion effects: The role of economic structure? Journal of Banking \& Finance 35(1), 130-141.

Chitkasame, T. and Tansuchat, R. (2019). An Analysis of Contagion Effect on ASEAN Stock Market Using Multivariate Markov Switching DCC GARCH. Thai Journal of Mathematics, Special Issue: Structural Change Modeling and Optimization in Econometrics. 135-152.

Billio, M., and Caporin, M. (2005). Multivariate Markov switching dynamic conditional correlation GARCH representations for contagion analysis. Statistical methods and applications, 14(2), 145-161.

Bollerslev, T. (1990). Modelling the coherence in short-run nominal exchange rates: a multivariate generalized ARCH model. The review of economics and statistics, 498-505.

Celık, S. (2012). The more contagion effect on emerging markets: The evidence of DCC-GARCH model. Economic Modelling, 29(5), 1946-1959.

Chancharoenchai, K., \& Dibooglu, S. (2006). Volatility spillovers and contagion during the Asian crisis: evidence from six Southeast Asian stock markets. Emerging Markets Finance and Trade, 42(2), 4-17.

Chaudhuri, K., \& Kumar, A. (2015). A Markov-Switching Model for Indian Stock Price and Volume. Journal of Emerging Market Finance, 14(3), 239-257.

Chauvet, M., \& Potter, S. (2000). Coincident and leading indicators of the stock market. Journal of Empirical Finance, 7(1), 87-111.

Chiang, T. C., Jeon, B. N., and Li, H. (2007). Dynamic correlation analysis of financial contagion: Evidence from Asian markets. Journal of International Money and Finance, 26(7), 1206-1228.

Cominetta, M. (2016). Financial contagion: A new perspective (and a new test) (European Stability Mechanism Working Paper No. 12).

Corsetti, G., Pericoli, M., and Sbracia, M. (2005). Some contagion, some interdependence: More pitfalls in tests of financial contagion. Journal of International Money and Finance, 24(8), 1177-1199.

Dimitriou, D., Kenourgios, D., and Simos, T. (2013). Global financial crisis and emerging stock market contagion: A multivariate FIAPARCH-DCC approach. International Review of Financial Analysis, 30, 46-56.

Dungey, M. and Diana Zhumabekova. (2001). Testing for contagion using correlations: some words of caution. No. 2001-09. Federal Reserve Bank of San Francisco, 2001.

Engle, R. (2002). Dynamic conditional correlation: A simple class of multivariate generalized autoregressive conditional heteroskedasticity models. Journal of Business \& Economic Statistics, 20(3), 339-350

Forbes, K.J. and Rigobon, R. (2002). No contagion, only interdependence: Measuring stock market comovements. The Journal of Finance, 57(5), 2223-2261.

Glick R. and Rose, A.K. (1999). "Contagion and trade: Why are currency crises regional?," Journal of International Money and Finance, vol. 18(4), 603-617. 
Glosten, L.R., Jagannathan, R. and Runkle, D.E. (1993). On The Relation between The Expected Value and The Volatility of Nominal Excess Return on stocks. Journal of Finance 48, pp 1779-1801.

Hamilton J.D. (1989) A new approach to the economic analysis of nonstationary time series and the business cycle. Econometrica 57, 357-384

Hemche, O., Jawadi, F., Maliki, S. B., \& Cheffou, A. I. (2016). On the study of contagion in the context of the subprime crisis: A dynamic conditional correlation-multivariate GARCH approach. Economic Modelling, 52, 292-299.

Hess, M. K. (2003). What drives Markov regime-switching behavior of stock markets? The Swiss case. International Review of Financial Analysis, 12(5), 527-543

Hwang, I., In, F. H., \& Kim, T. S. (2010). Contagion effects of the US subprime crisis on international stock markets. In Finance and Corporate Governance Conference.

Kali, R., and Reyes, J. (2010). Financial contagion on the international trade network. Economic Inquiry, 48(4), 1072-1101.

Kaminsky, G. and Reinhart, C. 2001. "Financial Markets in Times of Stress,” NBER Working Paper, No. 8569.

Kodres, L. E., and Pritsker, M. 2002. A rational expectations model of financial contagion. The journal of finance, 57(2), 769-799.

Linne, T. (2002). A Markov switching model of stock returns: an application to the emerging markets in central and eastern Europe. In East European Transition and EU Enlargement (pp. 371-379). Physica, Heidelberg.

Liu, X., Margaritis, D., \& Wang, P. (2012). Stock market volatility and equity returns: Evidence from a two-state Markov-switching model with regressors. Journal of Empirical Finance, 19(4), 483-496.

Longstaff, F.A. (2010) The subprime credit crisis and contagion in Financial markets. Journal of Financial Economics, 97, 3, $436-450$.

Loretan, M., and English, W.B. (2000). Evaluating correlation breakdowns during periods of market volatility (International Finance Discussion Paper No. 658, Board of Governors of the Federal Reserve System).

Mendoza, E.G. and Quadrini, V. (2010). Financial globalization, financial crises and contagion. Journal of Monetary Economics. 57, 1, 24-39.

Mollah, S., Quoreshi, A.S., and Zafirov, G. (2016). Equity market contagion during global financial and Eurozone crises: Evidence from a dynamic correlation analysis. Journal of International Financial Markets, Institutions and Eurozone crises: Evidence from a dynamic correlation analysis. Journal of International Financial Markets, Institutions and Money, 41, 151-167.

Nieh, C. C., Kao, Y. S., \& Yang, C. H. (2011). The Asymmetric Contagion from the US Stock Market around the Subprime Crisis. In Studies On Financial Markets In East Asia (pp. 19-39).

Orskaug, E. (2009). Multivariate DCC-GARCH Model-with Various Error Distributions. SAMBA/19/09, Norwegian University of Science and Technology.

Pastpipatkul, P., Yamaka, W., \& Sriboonchitta, S. (2016). Analyzing financial risk and co-movement of gold market, and indonesian, philippine, and thailand stock markets: dynamic copula with markov-switching. In Causal Inference in Econometrics (pp. 565-586). Springer, Cham.

Rigobon, R. (2019). Contagion, Spillover, and Interdependence. Economía, 19(2), 69-99.

Sibel Celik (2012). The more contagion effect on emerging markets:The evidence of DCC-GARCH model. Econimic Modelling 29.1946-19Money, 41, 151-167.

Salgado,M.R., Ricci, M.L.A., and Caramazza, M. F. (2000). Trade and financial contagion in currency crises (No. 0-55). International Monetary Fund.

Schaller, H., \& Norden, S. V. (1997). Regime switching in stock market returns. Applied Financial Economics, 7(2), 177-191.

Tansuchat, R., \& Yamaka, W. (2018, March). Markov-Switching ARDL Modeling of Parboiled Rice Import Demand from Thailand. In International Symposium on Integrated Uncertainty in Knowledge Modelling and Decision Making (pp. 373-384). Springer, Cham.

Wongutai, N., Yamaka, W., \& Tansuchat, R. (2018, March). European Real Estate Risk and Spillovers: Regime Switching Approach. In International Symposium on Integrated Uncertainty in Knowledge Modelling and Decision Making (pp. 433-444). Springer, Cham.

Zhanyun, W. (2018). Research on the mechanism of the spatial contagion of global financial crises: From the perspective of pure contagion. Chinese Journal of Urban and Environmental Studies, 6(1), 1-16. 